\title{
Modified rat limb transplantation model for VCA experiments: difficulties and know-how of vascularized bone marrow flap
}

\author{
Jong Won Hong ${ }^{1}$, Jung Hyum Lim² ${ }^{2}$ Won Jai Lee ${ }^{1}$ \\ ${ }^{1}$ Department of Plastic and Reconstructive Surgery, Yonsei University College of Medicine, Seoul, Korea \\ ${ }^{2}$ Institute for Human Tissue Restoration, Yonsei University College of Medicine, Seoul, Korea
}

Background: Diverse researches in vascularized composite tissue allotransplantation (VCA), represented by face/hand transplantation, is performed by a rat-based animal experiment. In the early, limb transplantation was mainly used, but in recently, a modified model is used for the proper purpose of research. We used vascularized femoral bone marrow flap for immune tolerance research. We would like to analyze and present the results of the high technique animal experiments area.

Methods: Donor used a 7-8-week-old Brown Norway rat (BN, RTn). Recipients were 7-8-week-old Lewis rats (LEW, RT1). Femoral bone was used as the target materials for the immune tolerance effect. Pedicle used femoral artery and vein. To confirm flap survival from the outside, a $2 \times 2 \mathrm{~cm}$ inguinal skin flap based on a lateral circumflex vessel branching from the femoral vessel was included. Flap was classified as osteocutaneous flap. Immunosuppression, FK-506, was given daily IP. Blood samples were taken 3 days, and once a week after operation. We keep the rats for 8 weeks.

Results: Total 30 VCAs were performed. Animal experiments were performed by one surgeon (JWH). It took approximately 6 hours from initial preparation to cleaning. Vascular anastomosis was connected to one artery and one vein. Out of a total of 30 animals, five died immediately after surgery. Even if the operation was successful, 12 cases died within 2 weeks. There were many cases of death within 1-2 days after blood sampling when anesthesia was insufficient. Conversely, there were several cases of death when anesthesia was excessive. In addition, there were cases of death in lower body temperature or weight loss.

Conclusions: Vascularized bone marrow transplantation is a technically difficult and time-consuming operation. Body temperature, pain during surgery, and dietary management in postoperative period are absolutely necessary. Invasive procedures such as orbital blood sampling after surgery should also be performed delicately.

Corresponding author: Jong Won Hong

E-mail: hsaturn@hanmail.net

(C) The Korean Society for Transplantation

This is an Open Access article distributed under the terms of the Creative Commons Attribution Non-Commercial License (http://creativecommons.org/licenses/by-nc/4.0/) which permits unrestricted non-commercial use, distribution, and reproduction in any medium, provided the original work is properly cited. 